\title{
Measurement of Pulmonary Capillary Blood Flow in Infants by Plethysmography
}

\author{
J. Stocks, K. Costeloe, C. P. Winlove, and S. Godfrey \\ From the Department of Pediatrics and Neonatal Medicine, and Department of Medical Physics \\ Hammersmith Hospital, London W12 OHS, England
}

A B S T R A C T An accurate method for measuring effective pulmonary capillary blood flow ( $\dot{Q} c$ eff) in infants has been developed with an adaptation of the plethysmographic technique. Measurements were made on 19 preterm, 14 small-for-dates, and 7 fullterm normal infants with a constant volume whole body plethysmograph in which the infant rebreathed nitrous oxide.

There was a highly significant correlation between Qc eff and body weight, and this relationship was unaffected by premature delivery or intrauterine growth retardation. Mean QC eff in preterm, smallfor-dates, and fullterm infants was 203, 208, and 197 $\mathrm{ml} \mathrm{min}^{-1} \mathrm{~kg}^{-1}$, respectively, with no significant differences between the groups. A significant negative correlation existed between $\dot{Q}_{c}$ eff and haematocrit in the preterm infants. There was no relationship between weight standardized $\dot{Q} c$ eff and postnatal age in any of the groups.

With this technique, it was possible to readily recognise the presence of rapid recirculation (indicative of shunting) in several of the infants, suggesting that rebreathing methods for the assessment of $\dot{Q}_{c}$ eff should not be applied indiscriminately during the neonatal period. By taking care to overcome the potential sources of technical error, it was possible to obtain highly reproducible results of $\dot{Q}_{C}$ eff in infants over a wider age range than has been previously reported.

\section{INTRODUCTION}

Numerous methods for the measurement of effective pulmonary capillary blood flow (Q்c eff) ${ }^{1}$ have been

Received for publication 26 July 1976 and in revised form 25 October 1976.

${ }^{1}$ Abbreviations used in this paper: BTPS, body temperature and pressure, saturated; CVPE, coefficient of variation of paired estimates; fc, cardiac frequency; FA, alveolar fractional concentration; $\dot{Q} c$ eff, effective pulmonary capillary blood flow; $\mathrm{R}$, respiratory exchange ratio; $\mathrm{SFD}$, small-fordates; $\mathrm{SV}$, stroke volume; $\dot{\mathrm{V}} \mathrm{O}_{2}$, oxygen consumption. developed for use in adults (1-4), but although there are some data for infants, (5-7) these are relatively scarce, especially after the 1 st wk of life. This is mainly because only those methods which require no active cooperation on the part of the subject can be applied to infants. Moreover, there is an additional problem in obtaining reliable data during the early neonatal period, since there is considerable evidence to suggest that many healthy newborn infants, especially those born prematurely, continue to have some left to right shunt during at least the lst wk of life (8-11). This would result in rapid recirculation, disturbing the uptake of soluble inert gases and thereby causing $\dot{Q} c$ eff to be underestimated.

There is remarkably little data on $\dot{Q} c$ eff after the 1st wk of life, when atelectasis and shunting are far less likely to confuse the results, and we can find no published data after $2 \mathrm{wk}$ postnatal age. We have therefore developed a noninvasive method, which is an adaptation of the Lee and DuBois plethysmographic technique (4) with nitrous oxide $\left(\mathrm{N}_{2} \mathrm{O}\right)$, to obtain further information on $Q_{C}$ eff in infants over a wider age range. This method is based on the fact that if a subject breathes $\mathrm{N}_{2} \mathrm{O}$ while inside the plethysmograph, the pressure in the box will decrease as gas is absorbed by the blood flowing through the pulmonary capillaries. Qc eff can be calculated from the rate of uptake of $\mathrm{N}_{2} \mathrm{O}$, providing its solubility in blood and the mean alveolar concentration are known. The whole-body infant plethysmograph that we have used is of the closed or "constant volume" type, and particular attention has been paid to the characteristics of the measurement system so that reliable and reproducible results could be obtained.

\section{METHODS}

Apparatus. The plethysmograph was a modified Cross box (12) made from aluminium and Perspex (acrylic, I.C.I. Organics, Inc., Stamford, Conn.) which had been built up at one end of the perspex lid to enable the rebreathing apparatus, which was supported within it, to be attached to the infant after the main lid had been closed. It had a total vol of 31.5 
liter when empty and could be used for measurements in infants up to $5.0 \mathrm{~kg}$ body weight.

It proved to be extremely difficult to design an infant plethysmograph that was completely airtight, especially when rapid access to the infant was essential in case of emergencies, and the characteristics of the present system were therefore carefully analyzed. The time constant of the plethysmograph (i.e. the time in which an induced pressure difference within the box will fall to half its initial value) varied slightly from day to day but was approximately $117 \mathrm{~s}$, and although this was a relatively small leak, it was of significance when measuring a pressure change over a 20-s period. Consequently we devised a leak correction factor which was applied to measured pressure changes before calculation of Q $\dot{c}$ eff (see Appendix 1). A differential pressure transducer (Mercury Electronics micromanometer, Mercury Electronics Corp., Mineola, N. Y.) was used to detect any change in pressure within the plethysmograph relative to an aluminium compensating chamber of similar volume. The latter was maintained at mean atmospheric pressure by the presence of a small variable leak which was regulated by a fine needle valve. This arrangement was found to be essential to eliminate artifacts resulting from alterations in ambient barometric pressure or temperature. The pressure between the plethysmograph and compensating chamber could be equalized by a valve, and the box could be vented to atmosphere by means of a wide bore metal stopcock in the wall of the chamber. The amplitude and phase frequency responses for the whole system were flat to within $\pm 5 \%$ from 0 to 10 cycles/s, which was satisfactory for the present study.

The rebreathing apparatus was made from Perspex, and consisted of a tube (internal diameter $7 \mathrm{~mm}$ ) from which two pneumatically-operated valves communicated either directly to air within the plethysmograph, or into a $500-\mathrm{ml}$ rubber rebreathing bag (Air Med Ltd.). The valves were operated individually by miniature bellows outside the plethysmograph, so that the infant could be switched from air into a rebreathing mixture, or vice versa, as required. The valves could withstand pressures of up to $75 \mathrm{~cm} \mathrm{H}_{2} \mathrm{O}$ without leaking and therefore prevented any seepage of $\mathrm{N}_{2} \mathrm{O}$ into the baby before the rebreathing period, and similarly prevented any loss of $\mathrm{N}_{2} \mathrm{O}$ from the system during rebreathing. A full description of this type of rebreathing apparatus has been given elsewhere (13).

An infant face mask (Rendell Baker size 0, 1, or 2), containing a sampling point for gas analysis, was attached to the apparatus which was supported within the plethysmograph by an adjustable horizontal rod, and which could be easily manipulated into position once the infant was in situ. The mask plus apparatus had a total dead space of $4 \mathrm{ml}$ and a resistance of $3.5 \mathrm{~cm} \mathrm{H}_{2} \mathrm{O}$ liter $^{-1} \mathrm{~s}^{-1}$ at a flow rate of $100 \mathrm{ml} \mathrm{s}^{-1}$. Sterilization was achieved by immersion of the whole apparatus in "Cidex" solution (activated glutaraldehyde-Ethicon Inc., Somerville, N. J.) for $10 \mathrm{~min}$ after each study. The temperature within the rebreathing bag was measured during each study by an enclosed thermocouple.

A fast response $\mathrm{N}_{2} \mathrm{O}$ meter (Grubb Parsons Med. 1) was used for continuous analysis of $\mathrm{N}_{2} \mathrm{O}$ concentration during rebreathing. At a sampling rate of $60 \mathrm{ml} \mathrm{min}^{-1}$ this had a $95 \%$ response time of $1.0 \mathrm{~s}$, and a time lag of $1.5 \mathrm{~s}$ which was allowed for in the calculations. This instrument was extremely stable after calibration, which was checked frequently, and was insensitive to water vapour pressure and to $\mathrm{CO}_{2}$ in concentrations well above $50 \%$.

Recordings were made on photographic paper with a UV light recorder (S.E. Labs: S.E. 3006) in conjunction with an electromedical multichannel amplifier (S.E. Labs: S.E. 49100) into which the electrocardiograph preamplifier (S.E. 4917) was incorporated.

Procedure. Disposable electrocardiograph leads (Dracard Ltd) were attached to the wrists and right leg of the infant before he was placed supinely in the plethysmograph. Disposable diapers were used to keep the head centrally positioned. The main lid was then closed. Once the infant was asleep, the rebreathing apparatus was manipulated into place. The mask was sealed around the nose and mouth with therapeutic putty (J. A. Carter Ltd, Wiltshire) to achieve an airtight fit. With the mask in position, the infant was allowed to breathe air through the side valve of the apparatus, and the plethysmograph was closed by attaching the upper lid. No recordings were taken until thermal equilibration had been reached, as shown by the attainment of a stable base line for box pressure. This usually took between 5 and 10 min after closing the box, during which time it was frequently vented to atmosphere.

The box was then calibrated in terms of volume change by slowly withdrawing $20 \mathrm{ml}$ of gas from the box at a constant flow rate $\left(1 \mathrm{ml} \mathrm{s}^{-1}\right)$ with an accurately calibrated peristaltic pump (Watson-Marlow), and recording the resultant pressure change. The leak constant was measured from the approximately exponential increase in pressure over the 20-s period after the end of the withdrawal as gas slowly leaked back into the box. This was later used to calculate the leak correction factor which was then applied both to the calibration signal and to the measured box pressure changes during the experimental period. Measurement of the calibration factor and leak constant were performed in this manner to overcome any potential errors arising from adiabatic to isothermal changes (see Appendix 2).

A control run was then obtained by switching the infant from breathing air from the box to rebreathing from the bag, which had been filled with $50-150 \mathrm{ml}$ of $30 \% \mathrm{O}_{2}$ and $70 \%$ $\mathrm{N}_{2}$. The volume was adjusted for each experiment so that it approximated the infant's expected lung volume, thus facilitating rapid equilibration. When filled with this amount of gas the bag remained completely flaccid because of its large capacity. The infant was allowed to rebreathe the gas mixture for approximately $40 \mathrm{~s}$ while a simultaneous recording of electrocardiograph and changes in box pressure was taken, after which he was switched back to air. The resultant slope of the trace of box pressure against time represented the loss of gas from the system due to the falling respiratory exchange ratio $(\mathrm{R})$ during rebreathing, and was later subtracted from the loss of gas during $\mathrm{N}_{2} \mathrm{O}$ rebreathing.

A second "control" slope was obtained on 18 occasions by allowing the infant to rebreathe from a bag containing $7 \% \mathrm{CO}_{2}, 30 \% \mathrm{O}_{2}$, and $63 \% \mathrm{~N}_{2}$. Since $\mathrm{CO}_{2}$ excretion $\left(\mathrm{VCO}_{2}\right)$ virtually ceases under these conditions (14) oxygen consumption $\left(\mathrm{VO}_{2}\right)$ could be assessed by measuring the rate of uptake of gas between 10 and $30 \mathrm{~s}$ after the commencement of rebreathing the $7 \% \mathrm{CO}_{2}$ gas mixture, i.e. when the slope of uptake was linear after the initial equilibration period. $\dot{\mathrm{V}} \mathrm{CO}_{2}$ was calculated as the difference between $\dot{\mathrm{VO}}_{2}$ and the uptake of gas during the original control slope, and from this it was possible to calculate the change in $R$ during the rebreathing period. The magnitude of this $R$ effect is summarized in Table $I$, and emphasizes the importance of performing a control slope before every $\mathrm{N}_{2} \mathrm{O}$ run, and of measuring the rate of uptake from the system during exactly the same time period in the control slope as in the $\mathrm{N}_{2} \mathrm{O}$ run.

The infant was then switched into the bag that had been refilled with the same volume of $30 \% \mathrm{O}_{2}$ and $70 \% \mathrm{~N}_{2} \mathrm{O}$, which he rebreathed for approximately $40 \mathrm{~s}$ while a simultaneous recording of box pressure, electrocardiograph, and $\mathrm{N}_{2} \mathrm{O}$ con- 
TABLE I

Summary of Results Demonstrating the Change in $R$ during Rebreathing *

\begin{tabular}{|c|c|c|c|c|}
\hline \multicolumn{2}{|c|}{ Time } & \multirow{2}{*}{$\frac{\text { Control slope }}{m l \mathrm{~min}^{-1} \mathrm{~kg}^{-1}}$} & \multirow{2}{*}{$\frac{7 \% \mathrm{CO}_{2} \text { slope }\left(\mathrm{V}_{2}\right)}{m l \min ^{-1} \mathrm{~kg}^{-1}}$} & \multirow[t]{2}{*}{$\mathbf{R}$} \\
\hline & & & & \\
\hline \multirow[t]{2}{*}{$1-10$} & Mean & 2.4 & (6.8) & 0.64 \\
\hline & SEM & 0.20 & & 0.03 \\
\hline \multirow[t]{2}{*}{$11-20$} & Mean & 3.4 & 6.8 & 0.50 \\
\hline & SEM & 0.22 & 0.33 & 0.03 \\
\hline \multirow[t]{2}{*}{$21-30$} & Mean & 4.1 & 6.8 & 0.39 \\
\hline & SEM & 0.27 & 0.33 & 0.03 \\
\hline
\end{tabular}

* This table shows loss of volume from the system during rebreathing of $70 \% \mathrm{~N}_{2}, 30 \% \mathrm{O}_{2}$ (control slope) and during rebreathing of a mixture containing $7 \% \mathrm{CO}_{2}$, so that $\mathrm{O}_{2}$ uptake $\left(\mathrm{V}_{2}\right)$ could be assessed. The $\mathrm{R}$ was derived from these data as described in the text.

$\$$ Time after switching into rebreathing system.

centration was taken. The flow rate of $60-90 \mathrm{ml} \mathrm{min}^{-1}$ was regulated by a small airtight diaphragm pump which returned the gas to the rebreathing bag after sampling to prevent changes in the volume of the system. (Gases were also circulated through this system during control runs.) The temperature within the bag, which varied slightly from day to day but which was usually about $25^{\circ} \mathrm{C}$, was recorded for each run.

The whole procedure was repeated until three satisfactory runs had been obtained in each infant, measuring the leak constant, calibration factor, and control slope before each period of $\mathrm{N}_{2} \mathrm{O}$ rebreathing, and allowing at least $10 \mathrm{~min}$ between each run to ensure the $\mathrm{N}_{2} \mathrm{O}$ was not detectable in expired gas. The study was approved by the Hospital Ethical Committee, and parental consent was obtained before the tests were performed.

Calculation of results. Fig. 1 shows a tracing obtained during a control run while rebreathing $30 \% \mathrm{O}_{2}$ and $70 \% \mathrm{~N}_{2}(\mathrm{~A})$ and that obtained during $\mathrm{N}_{2} \mathrm{O}$ rebreathing (B). The changes in mean box pressure relative to atmosphere were measured at 1-s intervals, corrected for leak as described in Appendix 1 and multiplied by the calibration factor to give the rate of uptake in $\mathrm{ml} \mathrm{s}^{-1}$, which was then converted to BTPS (body temperature and pressure, saturated).

The rate of uptake during the control run was subtracted from that during $\mathrm{N}_{2} \mathrm{O}$ rebreathing, and the corrected volume changes were carefully inspected for signs of irregularity or diminishing value, either of which could be indicative of recirculation. Qc eff was calculated during a period of time in which a steady state had been obtained, i.e. after the achievement of satisfactory equilibrium and before signs of any significant recirculation. This period of analysis was most frequently between 10 and $20 \mathrm{~s}$ after switching into $\mathrm{N}_{2} \mathrm{O}$, but was shortened to end between 15 and $19 \mathrm{~s}$ in approximately $25 \%$ of the infants who showed earlier signs of recirculation. Infants who recirculated before $14 \mathrm{~s}$ were excluded from the calculation as there was an insufficient period of time to enable accurate analysis to be performed.

Mean alveolar fractional concentration of $\mathrm{N}_{2} \mathrm{O}\left(\mathrm{FA}_{1} \mathrm{~N}_{2} \mathrm{O}\right)$ was read from the trace obtained during the period of analysis, by which time the inspired to expired $\mathrm{FA}_{1} \mathrm{~N}_{2} \mathrm{O}$ difference had usually fallen to less than 0.02 . The $\mathrm{N}_{2} \mathrm{O}$ concentration was multiplied by the ratio $\left(\mathrm{P}_{\mathrm{Bar}}-47\right) /\left(\mathrm{P}_{\mathrm{Bar}}-\mathrm{P}_{\mathrm{H}_{2} \mathrm{O}}\right)$ where $\mathrm{P}_{\mathrm{Bar}}$ is atmospheric pressure $(\mathrm{mm} \mathrm{Hg})$ and $\mathrm{P}_{\mathrm{H}_{2} \mathrm{O}}$ is water-vapour pressure $(\mathrm{mm} \mathrm{Hg})$ at room temperature, to correct for condensation in connecting tubing between the mask and analyser.

Qc eff was calculated by the following equation:

Q́c eff $\left(\mathrm{ml} \mathrm{min}^{-1} \mathrm{~kg}^{-1}\right)=\left(\dot{\mathrm{VN}}_{2} \mathrm{O} \times 60\right) /\left(\mathrm{FA}_{1} \mathrm{~N}_{2} \mathrm{O} \times \alpha \mathrm{N}_{2} \mathrm{O} \times \mathrm{wt}\right)$

where: $\dot{\mathrm{VN}}_{2} \mathrm{O}$ is the rate of uptake of $\mathrm{N}_{2} \mathrm{O}$ in $\mathrm{ml} \mathrm{s}^{-1}$ (BTPS)

and $\quad \alpha \mathrm{N}_{2} \mathrm{O}$ is Ostwald's solubility coefficient of $\mathrm{N}_{2} \mathrm{O}$ in blood at $37^{\circ} \mathrm{C}\left(=0.47 \mathrm{ml}(\mathrm{BTPS}) \cdot \mathrm{ml} \mathrm{blood}^{-1} \cdot\right.$ atmos$^{-}$ phere (BTPS) ${ }^{-1}$

and wt is body weight in kilograms.

This was divided by mean cardiac frequency (fc) during the period of analysis to give stroke volume (SV) per kilogram body weight.

Subjects. Studies were performed on 47 infants, but accurate measurements of Qc eff could only be made in 40 of these, due to the presence of poor equilibration in 3 , and definite evidence of shunting, as shown by rapid recirculation and low irregular uptake of $\mathrm{N}_{2} \mathrm{O}$, in 4 other infants. Six additional infants were initially found to have evidence of shunting when tested during the first 2 wk of life, but when retested after an interval of 1-3 wk were found to be normal, and the results from the latter occasions have been included.

Consequently, the measurements of 40 infants are reported here, of whom 7 were fullterm, 19 were preterm

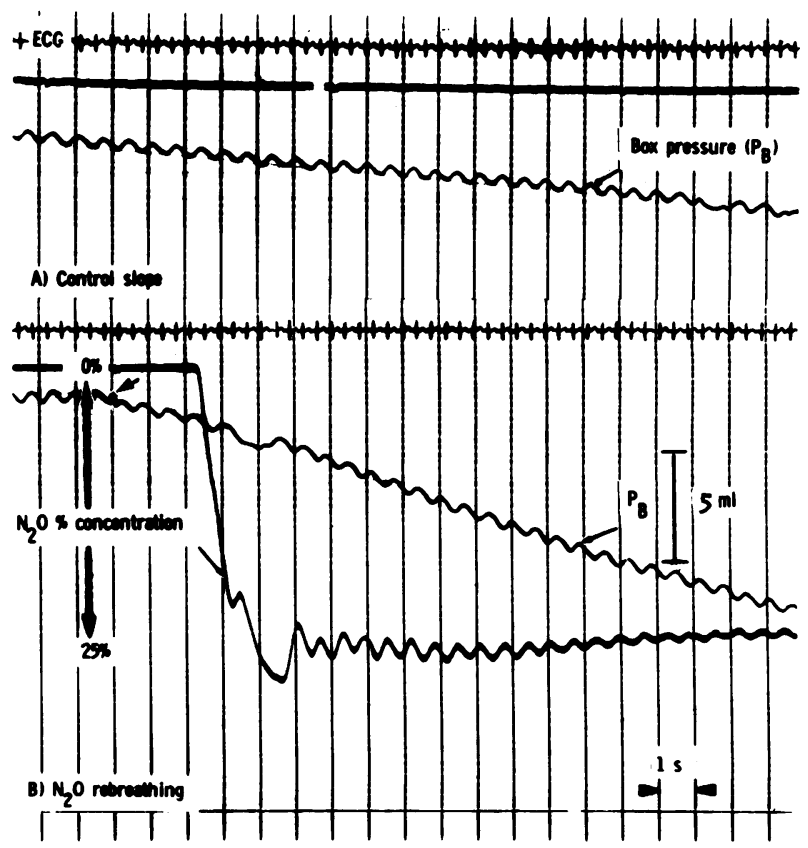

FIGURE 1 Record obtained A (above), while rebreathing $30 \% \mathrm{O}_{2}$ and $70 \% \mathrm{~N}_{2}$, and $\mathrm{B}$ (below), while rebreathing the $\mathrm{N}_{2} \mathrm{O}$ mixture. The small arrow marks the point at which the infant was switched into $\mathrm{N}_{2} \mathrm{O}$, the pump for sampling $\mathrm{N}_{2} \mathrm{O}$ being switched on $2 \mathrm{~s}$ later. The increased uptake of gas due to absorption of $\mathrm{N}_{2} \mathrm{O}$ by pulmonary blood flow can be seen from the steeper slope of the box pressure trace $\left(P_{B}\right)$ in $B$, compared to that seen during the control experiment (A). The box calibration in terms of volume change is shown. ECG, electrocardiograph. 
TABLE II

Clinical Details of Infants and Results

\begin{tabular}{|c|c|c|c|c|c|c|c|c|c|c|}
\hline Group & No. & $\mathrm{BW}^{*}$ & GA & $\begin{array}{c}\text { Post- } \\
\text { natal } \\
\text { age }\end{array}$ & Weight & Length & Hct & Qc eff & fc. & SV \\
\hline & & $k g$ & $w k$ & days & $k g$ & $c m$ & $\%$ & $m l m^{-1} \mathrm{~kg}^{-1}$ & $\min ^{-1}$ & $m l \mathrm{~kg}^{-1}$ \\
\hline Preterm & 1 & 1.20 & 29 & 37 & 1.90 & 44.0 & 39 & 230 & 140 & 1.64 \\
\hline \multirow[t]{18}{*}{ AGA } & 2 & 1.86 & 33 & 14 & 1.92 & 43.0 & 61 & 185 & 139 & 1.33 \\
\hline & 3 & 2.00 & 34 & 29 & 2.20 & 46.0 & 31 & 236 & 178 & 1.33 \\
\hline & 4 & 1.96 & 34 & 33 & 2.47 & 48.5 & 35 & 243 & 137 & 1.77 \\
\hline & 5 & 1.32 & 31 & 23 & 1.50 & 41.0 & 47 & 231 & 162 & 1.42 \\
\hline & 6 & 1.50 & 30 & 26 & 1.72 & 44.0 & 27 & 247 & 153 & 1.61 \\
\hline & 7 & 1.50 & 32 & 9 & 1.40 & 42.0 & 53 & 191 & 139 & 1.37 \\
\hline & 8 & 1.80 & 32 & 9 & 1.66 & 43.0 & 55 & 184 & 144 & 1.28 \\
\hline & 9 & 2.34 & 33 & 14 & 2.20 & 47.5 & 34 & 198 & 149 & 1.33 \\
\hline & 10 & 2.20 & 34 & 17 & 2.32 & 49.0 & 39 & 193 & 177 & 1.09 \\
\hline & 11 & 2.44 & 34 & 17 & 2.60 & 50.5 & 42 & 199 & 150 & 1.33 \\
\hline & 12 & 1.14 & 30 & 58 & 2.16 & 45.5 & 29 & 227 & 129 & 1.76 \\
\hline & 13 & 2.08 & 34 & 16 & 2.10 & 45.5 & 42 & 221 & 145 & 1.52 \\
\hline & 14 & 1.34 & 30 & 35 & 1.66 & 42.0 & 25 & 188 & 141 & 1.33 \\
\hline & 15 & 2.00 & 33 & 23 & 2.40 & 46.0 & 40 & 164 & 143 & 1.15 \\
\hline & 16 & 1.63 & 32 & 19 & 1.90 & 45.0 & 49 & 165 & 153 & 1.07 \\
\hline & 17 & 1.32 & 30 & 52 & 2.64 & 48.0 & 31 & 204 & 153 & 1.34 \\
\hline & 18 & 1.50 & 32 & 41 & 2.50 & 47.5 & 40 & 182 & 153 & 1.21 \\
\hline & 19 & 2.02 & 33 & 19 & 2.20 & 45.5 & 44 & 162 & 150 & 1.08 \\
\hline \multirow[t]{14}{*}{ SFD } & 20 & 1.70 & 38 & 9 & 1.85 & 46.0 & 65 & 237 & 147 & 1.61 \\
\hline & 21 & 1.96 & 38 & 8 & 2.08 & 46.5 & 60 & 217 & 150 & 1.45 \\
\hline & 22 & 2.02 & 35 & 13 & 2.08 & 46.5 & 52 & 269 & 152 & 1.77 \\
\hline & 23 & 2.12 & 36 & 14 & 2.24 & 45.0 & 39 & 175 & 143 & 1.22 \\
\hline & 24 & 1.50 & 35 & 23 & 2.09 & 46.5 & 48 & 215 & 126 & 1.70 \\
\hline & 25 & 1.53 & 35 & 26 & 1.96 & 42.5 & 47 & 186 & 146 & 1.27 \\
\hline & 26 & 2.08 & 37 & 21 & 2.33 & 48.0 & 48 & 209 & 154 & 1.36 \\
\hline & 27 & 1.46 & 35 & 28 & 1.88 & 43.0 & 38 & 173 & 154 & 1.12 \\
\hline & 28 & 1.08 & 31 & 36 & 1.55 & 41.0 & 40 & 227 & 159 & 1.43 \\
\hline & 29 & 2.15 & 36 & 25 & 2.40 & 45.0 & 42 & 235 & 159 & 1.48 \\
\hline & 30 & 1.70 & 35 & 23 & 2.22 & 47.5 & 35 & 220 & 159 & 1.34 \\
\hline & 31 & 1.03 & 34 & 54 & 2.05 & 43.0 & 29 & 211 & 162 & 1.31 \\
\hline & 32 & 2.50 & 37 & 7 & 2.40 & 46.0 & 53 & 180 & 136 & 1.32 \\
\hline & 33 & 2.20 & 36 & 14 & 2.26 & 48.0 & 41 & 162 & 144 & 1.12 \\
\hline \multirow[t]{7}{*}{ Fullterm } & 34 & 3.02 & 38 & 4 & 3.00 & 52.0 & 72 & 162 & 138 & 1.17 \\
\hline & 35 & 2.70 & 38 & 9 & 2.49 & 48.0 & 51 & 190 & 119 & 1.60 \\
\hline & 36 & 3.20 & 40 & 7 & 3.09 & 51.5 & 57 & 255 & 142 & 1.80 \\
\hline & 37 & 2.80 & 38 & 8 & 2.98 & 49.0 & 50 & 174 & 149 & 1.17 \\
\hline & 38 & 3.54 & 40 & 2 & 3.50 & 52.5 & 52 & 157 & 137 & 1.15 \\
\hline & 39 & 2.94 & 40 & 5 & 2.92 & 51.0 & 47 & 203 & 144 & 1.41 \\
\hline & 40 & 4.02 & 40 & 2 & 4.00 & 55.0 & 45 & 239 & 144 & 1.53 \\
\hline
\end{tabular}

* Abbreviations: AGA, appropriate weight for gestational age; BW, birth weight; GA, gestational age; Hct, hematocrit.

(appropriate weight for gestational age) and 14 were small-fordates (SFD) on the basis of birthweight below the 10th percentile for their gestational age, which was assessed clinically (15). Details of these infants are given in Table II and summarized in Table III. There was a significant difference $(P<0.05)$ in hematocrit between the fullterm and preterm infants at the time of testing.

Fullterm infants were studied unsedated, whereas many of the older preterm and SFD infants were lightly sedated with chloral hydrate $\left(40-50 \mathrm{mg} \mathrm{kg} \mathrm{kg}^{-1}\right)$ given orally with a feed before testing. To assess the effect, if any, of administering chloral, six cooperative infants were studied twice on the same day at exactly the same interval after a feed, firstly without and then with the sedation. Repeat measurements were made on 12 other infants at intervals between 2 and 14 days. 
TABLE III

Summary of Clinical Details of Infants and Results

\begin{tabular}{|c|c|c|c|c|c|c|c|c|c|c|}
\hline Group & No. & BW & GA & Weight & Length & $\begin{array}{l}\text { Postnatal } \\
\text { age }\end{array}$ & Het & Qc eff & fc & sv \\
\hline & & $\mathrm{kg}$ & $w k$ & $\mathrm{~kg}$ & $\mathrm{~cm}$ & days & $\%$ & $m l \min ^{-1} \mathrm{~kg}^{-1}$ & $m^{n} n^{-1}$ & $m l \mathrm{~kg}^{-1}$ \\
\hline \multicolumn{11}{|c|}{ Preterm AGA* } \\
\hline Mean & 19 & 1.75 & 32.1 & 2.08 & 45.4 & 25.8 & 40.2 & 202.6 & 149.2 & 1.34 \\
\hline SEM & & 0.09 & 0.4 & 0.08 & 0.6 & 3.2 & 2.2 & 6.2 & 2.9 & 0.05 \\
\hline \multicolumn{11}{|l|}{ SFD } \\
\hline Mean & 14 & 1.79 & 35.6 & 2.10 & 45.3 & 21.5 & 45.5 & 208.3 & 149.4 & 1.39 \\
\hline SEM & & 0.16 & 0.5 & 0.06 & 0.6 & 3.4 & 2.6 & 8.0 & 2.7 & 0.05 \\
\hline \multicolumn{11}{|l|}{ Fullterm } \\
\hline Mean & 7 & 3.17 & 39.1 & 3.14 & 51.3 & 5.3 & 53.4 & 197.1 & 139.0 & 1.40 \\
\hline SEM & & 0.18 & 0.4 & 0.18 & 0.8 & 1.1 & 3.4 & 14.3 & 3.7 & 0.10 \\
\hline
\end{tabular}

* AGA, appropriate weight for gestational age.

\section{RESULTS}

The individual results of the studies on the 40 normal infants are given in Table II, and summarized in Table III. Each result represents the mean of three measurements of Qc eff, fc, and SV obtained from each infant on the first occasion on which he was tested, Results obtained from repeat studies, either on the same day or on a subsequent occasion, are not

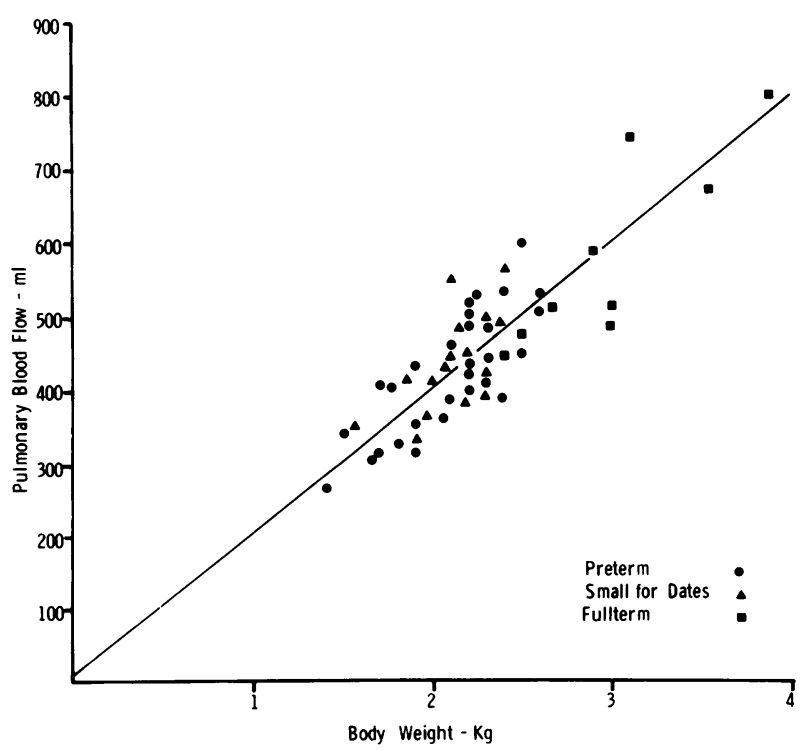

FIGURE 2 The relationship between $Q c$ eff and body weight in infants. included in this table to prevent biasing the results, but are discussed below. Qc eff has been calculated as $\mathrm{ml} \mathrm{min} \mathrm{mg}^{-1} \mathrm{~kg}^{-1}$ since oxygen consumption $\left(\mathrm{V}_{2}\right)$ of the newborn infant has been shown to be directly proportional to his body weight rather than his surface area $(16,17)$.

Absolute values of Qc eff ranged from 267 to 956

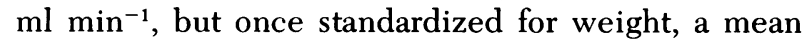
value of $205 \pm 20$ (SD) $\mathrm{ml} \mathrm{min}^{-1} \mathrm{~kg}^{-1}$ was obtained for the whole group of infants. Qc eff was highly significantly related to body weight $(r=0.82, P$ $<0.001)$ as shown in Fig. 2. This relationship was unaffected by premature delivery or intrauterine growth retardation.

The mean values for $\dot{Q} c$ eff in preterm, SFD, and fullterm infants were 203, 208, and $197 \mathrm{ml} \mathrm{min}^{-1}$ $\mathrm{kg}^{-1}$, respectively, which were not significantly different from one another $(P>0.1)$. Fc tended to be higher in the preterm and SFD infants than in fullterm infants but this was not statistically significant. There was no correlation between postnatal age and the weight standardised $Q \mathrm{c}$ eff in any group, but there was a significant negative correlation in preterm infants between hematocrit and Qc eff, as can be seen in Fig. $3(r=0.459, P<0.05)$. This relationship was not found in the other two groups. On the 18 occasions on which it was measured, Qc eff was found to be significantly correlated with $\mathrm{VO}_{2}(r=0.761, P<0.001)$ as shown in Fig. 4.

The reproducibility of the method of measuring Q $c$ eff was assessed by calculating the coefficient of variation of paired estimates (CVPE) (18) of the first two estimates of Qc eff, fc and, SV respectively, ob- 
tained from each infant on any one occasion. CVPE was also calculated for the mean of each set of the three estimates of Qc eff, fc, and SV obtained from the first and second occasions in the 12 infants who were studied twice, and for the 6 infants who were studied with and without sedation on the same day. The latter indicates any variation due to administration of chloral hydrate in addition to the residual variation between measurements made in the morning and afternoon. These results are summarized in Table IV. There was no significant difference $(P>0.2)$ between any of these comparisons and the CVPE for estimation of Qc eff was below $5 \%$ in every case.

\section{DISCUSSION}

This study has shown that, with suitable technical precautions, it is possible to obtain reproducible measurements of $\dot{Q} c$ eff in preterm, SFD and fullterm infants up to at least 2 mo of postnatal age. The high degree of reproducibility in the present study suggests that not only is the method reliable but that infants have attained a stable state with respect to Qc eff from 2 wk postnatal age onwards.

The way in which the accuracy of the leak correction factor was assessed is explained in Appendix I. It was found that changes in pressure over prolonged periods of time could be measured to within $1 \%$ accuracy by applying this correction factor and that the potential source of error arising from the slight leakage could therefore be satisfactorily eliminated.

The results from this study show that Qc eff is significantly related to both body weight and oxygen consumption in infants, suggesting that it is well

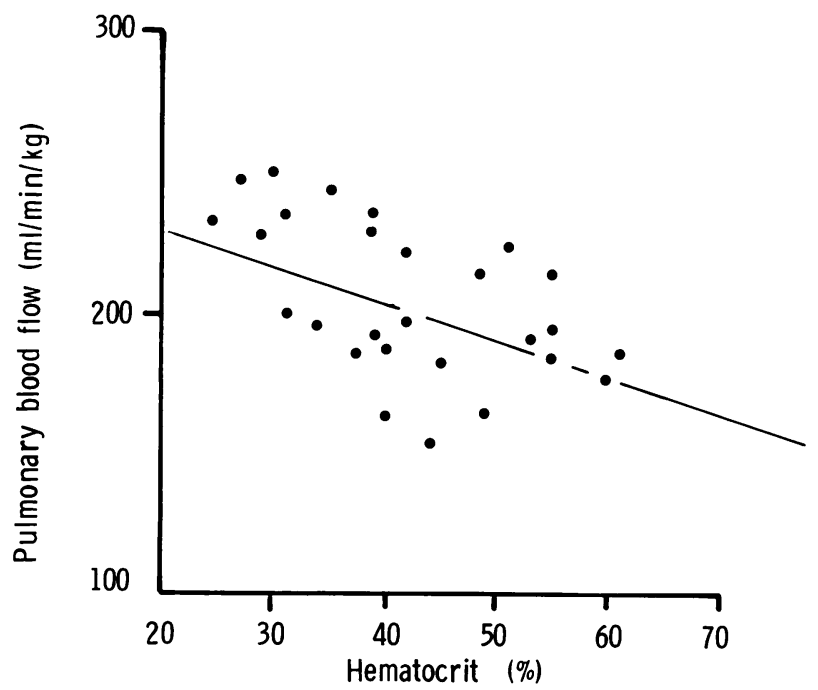

FIGURE 3 The relationship between Qc eff in premature infants and hematocrit.

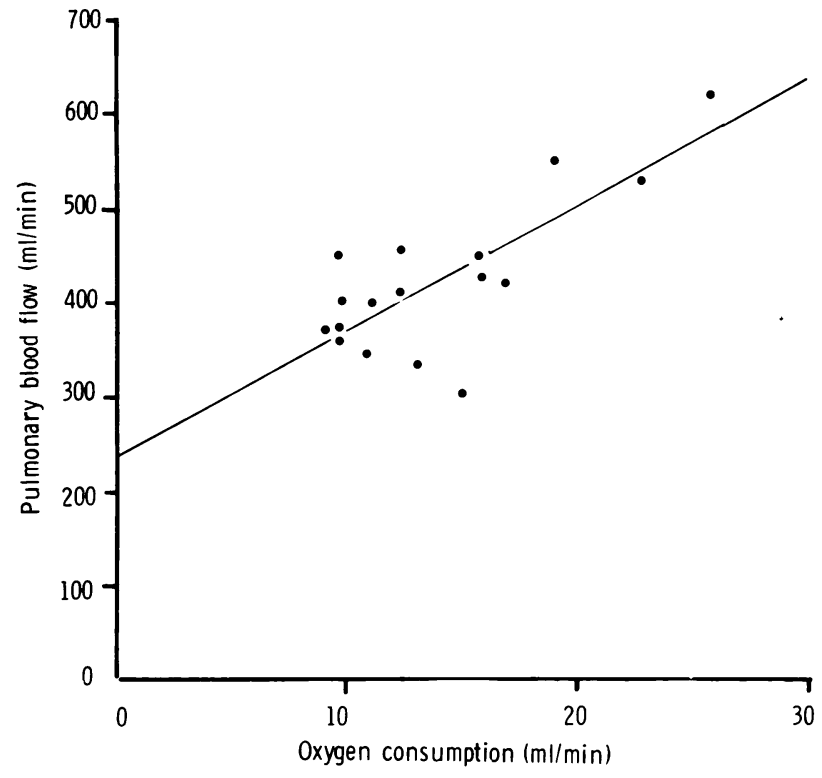

FIGURE 4 The relationship between Qce eff and oxygen consumption.

adapted to the metabolic needs of the rapidly growing infant. The mean value of $205 \pm 20$ (SD) $\mathrm{ml} \mathrm{min}^{-1}$ $\mathrm{kg}^{-1} \dot{Q} \mathrm{c}$ eff which was found in this study is considerably higher than that found in adults, since a cardiac output of 5-7 liter $\mathrm{min}^{-1}$ in a $70 \mathrm{~kg}$ adult $(1,4)$ represents values of only $70-100 \mathrm{ml} \mathrm{min}{ }^{-1}$ $\mathrm{kg}^{-1}$ when weight standardized. The difference may be due to the relatively higher oxygen consumption per unit body weight in infants. Even so, the results shown in Fig. 4, which agree substantially both in terms of $\dot{Q}_{c}$ eff and $\dot{\mathrm{VO}}_{2}$ when compared with other studies in infants $(5,19,20)$, imply a lower arterio-venous oxygen content difference in infants $(\simeq 30 \mathrm{ml} /$ liter) compared with the usual adult figure $(\simeq 50 \mathrm{ml} /$ liter $)$.

The negative correlation that we found between hematocrit and $\dot{Q c}$ eff in the premature infants is presumably a reflection of an adaptive increase in cardiac output in response to a decreased $\mathrm{O}_{2}$ carrying capacity of the blood. The lack of correlation in the other two groups is probably related to the fact that there were far fewer anemic infants in the SFD group and none amongst the fullterm infants.

Previously published results of Qc eff in infants have not commented on the reproducibility of their measurements and comparisons of data are therefore difficult. However, the results from this study are of the same order as those found previously in infants over a week of age. There do not appear to be any published data on $Q c$ eff in infants over 2 wk postnatal age.

The present data has been compared with previous results in Table $\mathrm{V}$, with results classified into three 
TABLE IV

Reproducibility of the Method

\begin{tabular}{|c|c|c|c|c|c|c|c|c|}
\hline & \multicolumn{3}{|c|}{ Same occasion $n=52$} & \multicolumn{3}{|c|}{ Different occasions $n=12$} & \multicolumn{2}{|c|}{ Same day $n=6$} \\
\hline & Rum 1 & & Run 2 & 1st & & 2nd & l'nsedated & Sedated \\
\hline \multicolumn{9}{|c|}{ Qc eff, $m l m^{\prime n} n^{-1} k^{-1}$} \\
\hline Mean & 202.9 & & 206.1 & 208.6 & & 209.8 & 189.5 & 181.0 \\
\hline SEM & 4.0 & & 4.1 & 7.7 & & 7.5 & 10.0 & 9.0 \\
\hline CVPE & & $4.6 \%$ & & & $4.8 \%$ & & & \\
\hline \multicolumn{9}{|c|}{ Heart rate/min } \\
\hline Mean & 146.5 & & 149.4 & 146.6 & & 151.3 & 155.0 & 152.5 \\
\hline SEM & 1.7 & & 1.5 & 4.4 & & 2.7 & 3.1 & 2.4 \\
\hline CVPE & & $2.4 \%$ & & & $4.9 \%$ & & & \\
\hline \multicolumn{9}{|c|}{ Stroke volume, $m l \mathrm{~kg}^{-1}$} \\
\hline Mean & 1.39 & & 1.38 & 1.43 & & 1.39 & 1.23 & 1.21 \\
\hline SEM & 0.02 & & 0.03 & 0.05 & & 0.06 & 0.08 & 0.06 \\
\hline CVPE & & $4.5 \%$ & & & $5.0 \%$ & & & \\
\hline
\end{tabular}

age groups. Some of the published data shows considerable scatter of weight standardized $\dot{Q}_{c}$ eff, especially during the perinatal period (6), so that although mean values of $\dot{Q}_{c}$ eff may be similar to those found in the present study, there appears to be a poor correlation between $\dot{Q} c$ eff and any parameter of body size. The various sources of technical error which would account for some of these discrepancies are discussed below.

Some of the limitations of various soluble gas techniques for measuring $\dot{Q} c$ eff have been indicated by Butler (22) and were given careful consideration in this study. It is obviously essential for good equilibration to occur between alveolar and bag gas (as shown by only a small difference between inspired and expired concentrations of $\mathrm{N}_{2} \mathrm{O}$ ), but this did not prove to be a problem in our healthy infants since a small initial bag volume was used. We have only had to exclude three infants on account of poor equilibration, all of whom were preterm infants exhibiting a periodic pattern of breathing. In the present method, $\mathrm{N}_{2} \mathrm{O}$ uptake is measured by a change in volume of the system and only mean $\mathrm{FA}_{1} \mathrm{~N}_{2} \mathrm{O}$ has to be measured. This has an advantage over superficially simpler rebreathing methods $(23,7)$ which depend critically on the accurate measurement of small changes in alveolar concentration of the inert soluble gas.

The time in which significant amounts of $\mathrm{N}_{2} \mathrm{O}$ recirculated varied considerably between the infants.
$25 \%$ of infants showed evidence of recirculation between 15 and $19 \mathrm{~s}$, while others showed no signs until 30 or $40 \mathrm{~s}$ of rebreathing. This individual variation may depend to some extent on the amount of stored body fat, in which $\mathrm{N}_{2} \mathrm{O}$ is known to be extremely soluble.

A further 10 infants (mean age 8 days) showed evidence of significant early recirculation, often before $10 \mathrm{~s}$, which precluded their use in this study. Of these infants, eight appeared to be clinically normal without any cardiac murmur, but showed exactly the same pattern as the remaining two infants, who had clinical signs of patent ductus arteriosus. This pattern of rapid recirculation was not seen in any infant over 16 days of postnatal age, and in the 6 of these 10 infants in whom it was possible to repeat the tests after an interval of 1-3 wk (mean age at retesting $=23$ days), recirculation time and $\mathrm{N}_{2} \mathrm{O}$ uptake were found to be entirely normal.

There is considerable evidence that the ductus arteriosus may remain patent for varying periods after birth $(8-11,24,25)$. However, previously published results of Qc eff in infants with soluble gas rebreathing techniques, have not mentioned the occurrence of rapid recirculation, indicative of shunting, in any of their subjects, despite the fact that many infants were studied within the 1 st $48 \mathrm{~h}$ of life. It is therefore difficult to know whether the initially low figures for Qc eff during the 1st 2 days of postnatal life which 
have been reported by some authors $(6,7)$, represent actual Qc eff or are falsely low due to rapid recirculation through a patent ductus.

The importance of measuring a control slope before $\mathrm{N}_{2} \mathrm{O}$ rebreathing is emphasized by the results summarized in Table I, where it can be seen that there may be considerable loss of gas from the system due to the respiratory exchange ratio, which falls rapidly during the rebreathing period. The fact that the $\mathrm{VO}_{2}$ calculated in the present study is similar to previously published values $(19,26,20)$ suggests that the technique we devised for demonstrating this $R$ effect is. probably valid. This change in volume of the system has in fact been ignored in several studies of $Q \mathrm{c}$ eff in infants $(6,7,23)$ which may greatly increase the difficulties both in measuring $\mathrm{FA}_{1} \mathrm{~N}_{2} \mathrm{O}$ accurately, and in detecting the onset of recirculation.

Despite the initial technical and mathematical problems in developing this technique, once it was established, it proved to be relatively simple to perform and was well tolerated by the infants. By taking care to overcome the potential errors of a rebreathing method and investigating the specific characteristics of the plethysmograph, it was possible to obtain reproducible results for Qc eff in infants.
The numerous random errors that can occur if a simpler method is used may well cancel one another out so that mean values of $\dot{Q}$ eff are of the right order. However, we feel the more complicated technique described here is worthwhile if confidence in the validity of individual measurements is required.

\section{APPENDIX 1}

The leak correction. When using a constant volume plethysmograph for measuring Qc eff, any slight leak becomes significant. The degree to which Qc eff would have been underestimated had we ignored the presence of the leak, depended not only upon the leak constant itself, but upon the magnitude of the pressure changes involved and the time period over which measurements were made, and therefore varied slightly from infant to infant. However, the application of the correction factor usually resulted in a correction of approximately $+7 \%$ over a 10 -s period. The way in which this factor was derived is explained below.

If an infant inhales a soluble gas within a leakproof plethysmograph, the rate of fall of box pressure with time,

$$
\mathrm{dP}_{\mathrm{B}(t)} / \mathrm{dt}=-\mathrm{f}_{(t)}
$$

where $f_{(t)}$ is the rate of change in box pressure with time, and is a function of the solubility coefficient, $F_{1} \mathrm{~N}_{2} \mathrm{O}$, and $Q c$ eff, but is presumed to be independent of box pressure. However, if the box is leaking it is a reasonable

TABLE V

Comparison of Present Data with Previously Published Values of $Q c$ eff in Infancy

\begin{tabular}{|c|c|c|c|c|c|c|c|c|c|c|c|}
\hline \multirow[b]{2}{*}{ Technique } & \multirow[b]{2}{*}{ Authors } & \multicolumn{3}{|c|}{$<2$ days } & \multicolumn{3}{|c|}{$2-7$ days } & \multicolumn{3}{|c|}{$>7$ days } & \multirow[b]{2}{*}{ Comment } \\
\hline & & $n$ & Age & Qc eff* & $n$ & Age & Qc eff* $*^{*}$ & $n$ & Age & Qc eff* & \\
\hline & & & $h$ & & & days & & & days & & \\
\hline \multirow{4}{*}{$\begin{array}{l}\text { Plethysmography } \\
\text { with } \mathrm{N}_{2} \mathrm{O}\end{array}$} & Present study & & - & & 5 & 4 & 203 & 2 & 8.5 & 182 & Fullterm \\
\hline & & & - & & & - & & 14 & 21.5 & 208 & SFD \\
\hline & & & - & & & - & & 19 & 26.0 & 203 & Preterm \\
\hline & Brady and Rigátto (5) & 8 & 23 & 175 & 11 & 3 & 178 & 8 & 9.0 & 205 & Fullterm \\
\hline $\begin{array}{l}\text { Reverse plethys- } \\
\text { mography } \\
\text { with } \mathrm{N}_{2} \mathrm{O}\end{array}$ & Orme et al. (21) & 5 & 20 & 165 & 5 & 2 & 188 & 2 & 7.5 & 179 & Preterm \\
\hline \multicolumn{12}{|l|}{$\begin{array}{l}\text { Simple rebreath- } \\
\text { ing methods }\end{array}$} \\
\hline \multirow[t]{2}{*}{ Freon } & Chu et al. (23) & 5 & 3.5 & 196 & 7 & 6 & 229 & 5 & 8.0 & 231 & Preterm \\
\hline & Cotton et al. (6) & 32 & 3.1 & 117 & 4 & 3 & 166 & & - & & $\begin{array}{r}\text { Preterm + } \\
\text { Fullterm }\end{array}$ \\
\hline $\mathrm{N}_{2} \mathrm{O}$ & Dinwiddie et al. (7) & 21 & 26.0 & 169 & & - & & & - & & Fullterm \\
\hline
\end{tabular}

The mean values of Qc eff have been calculated with the data from each infant on one occasion only, to prevent possible biasing of the means. Consequently, in any infant who was studied serially, only that value obtained on the first occasion within any particular age range has been used to calculate the mean results.

$n$ number of infants in each category.

* Qc eff has been expressed in $\mathrm{ml} \mathrm{min}^{-1} \mathrm{~kg}^{-1}$ throughout. 


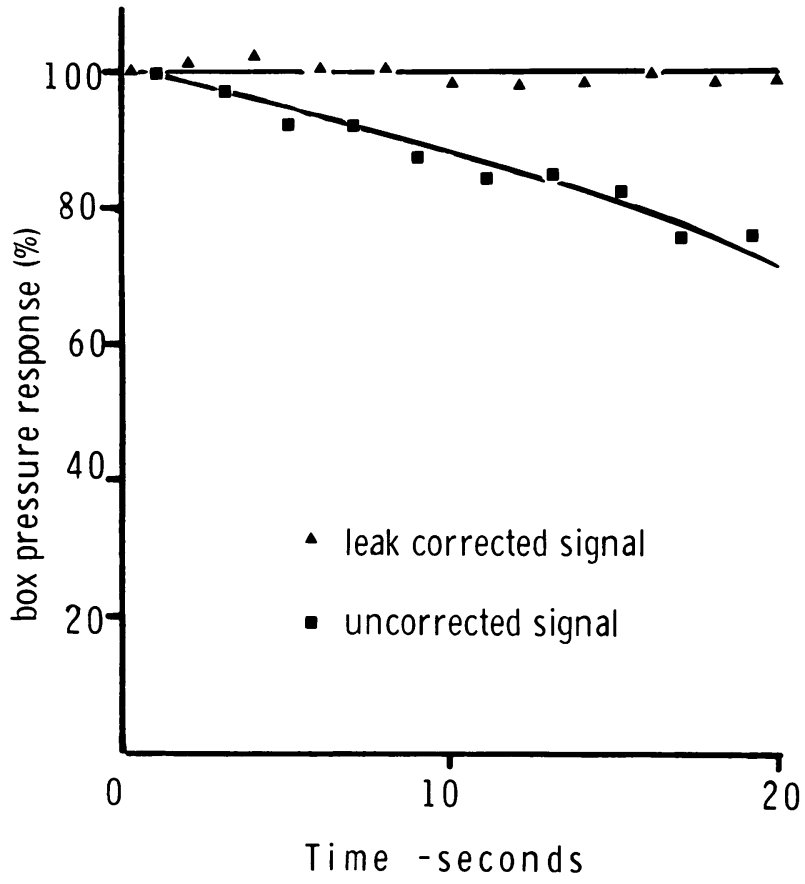

FIGURE 5 Graph showing the percentage accuracy of the uncorrected and the leak-corrected box pressure measurement against time. The rate of change of box pressure in response to a constant rate of withdrawal of air from the box was measured at second intervals and expressed as a percentage of the response obtained when there was no leak (see text). Similarly, the percentage response obtained after application of the leak correction factor was calculated.

first approximation to assume that the consequent rate of change of pressure is proportional to the difference between box pressure and atmospheric pressure. Equation (1) then becomes:

$$
\mathrm{dP}_{\mathrm{B}(t)} / \mathrm{dt}=\lambda\left(\mathrm{P}_{\mathrm{Bar}}-\mathrm{P}_{\mathrm{B}}\right)-\mathrm{f}_{(t)}
$$

where $P_{B a r}$ is atmospheric pressure and $\lambda$ is the leak constant. In this case the term $\left(P_{(B a r)}-P_{B}\right)$ represents the leakage of air into the box, and is related to the time constant $\left(t_{\frac{1}{2}}\right)$ by the equation $\lambda=\log _{\mathrm{e}}{ }^{2} / t_{\frac{1}{2}}$, while $f_{(t)}$ represents the uptake of $\mathrm{N}_{2} \mathrm{O}$ by the infant.

The solution to this equation is:

$$
P_{\mathrm{B}(t)}=\left(\mathrm{P}_{\mathrm{B}}{ }^{0}-\mathrm{P}_{\mathrm{Bar}}\right) \mathrm{e}^{-\lambda t}+\left(\mathrm{P}_{\mathrm{Bar}}-\mathrm{e}^{-\lambda t}\right) \int_{0}^{t} \mathrm{f}_{(t)} \mathrm{e}^{\lambda t} \mathrm{~d} t
$$

where $\mathrm{P}_{\mathrm{B}}{ }^{0}$ is the initial box pressure. This equation enables $\lambda$ to be measured, since if there is no uptake of gas by the infant (i.e. before rebreathing), the second term is zero and hence, after withdrawal of gas from the box, a semilogrithmic plot of $\mathrm{P}_{\mathrm{B}(t)}$ against time should yield a straight line, the slope of which is $-\lambda$. Knowing $\lambda$ it is then possible to use this equation to determine $f_{(t)}$ from the measured values of $\mathrm{P}_{\mathrm{B}(t)}$ during rebreathing.

If the box is vented at the beginning of the rebreathing period $P_{B}{ }^{\circ}=P_{B a r}$, and differentiation of equation (3) then gives:

$$
\mathrm{f}_{(t)}=-\frac{\left[\mathrm{d} \theta_{(t)}\right]^{-\lambda t}}{\mathrm{~d} t}
$$

where

$$
\theta_{(t)}=\mathrm{e}^{\lambda t}\left(\mathrm{P}_{\mathrm{B}(t)}-\mathrm{P}_{\mathrm{Bar}}\right)
$$

Thus, from the measured values of $\mathrm{P}_{\mathrm{B}(t)}$ and the known value of $\lambda$, one may compute $\theta_{(t)}$, differentiate it, multiply the result by $\mathrm{e}^{-\lambda t}$, and so obtain $\mathrm{f}_{(t)}$. This calculation can be done by hand, but in practice is performed rapidly with the aid of a simple computer program.

The accuracy of the leak correction factor was assessed in the following manner. Gas was withdrawn from the box at a constant rate of $1 \mathrm{ml} \mathrm{s}^{-1}$ for $20 \mathrm{~s}$ while a recording of change in box pressure was made, with the leak constant being measured at the end of the withdrawal period. The rate of change in box pressure was measured at second intervals and calculated as a percentage of the response obtained during the lst s of withdrawal, when the leak was insignificant. The leak correction factor was then applied, and the corrected signal was again calculated as a percentage of the initial response. The results are shown in Fig. 5 where it can be seen that the uncorrected response gradually decreases with time, resulting in a mean response of $88 \%$ over a 20 -s period, whereas the mean leak corrected response was $99.2 \%$, showing an error of less than $1 \%$.

\section{APPENDIX 2}

Adiabatic and isothermal changes in the plethysmograph. When using a closed plethysmograph, pressure changes are recorded by a manometer and represent corresponding changes in volume within the box. However, the pressure-volume relationship of a given mass of gas varies according to the amount of heat entering or leaving the system, and during the measurement of $\dot{Q} c$ eff the rate of heat exchange will depend both upon the thermal properties of the box and the rate of gas uptake.

A series of experiments in which air was withdrawn from the box at different frequencies indicated that, over the range of frequencies normally encountered experimentally, the box reacts in a manner that is neither perfectly adiabatic nor isothermal, and the calibration factor will therefore vary depending upon the speed of withdrawal. Similarly, the subsequent return of box pressure to atmospheric pressure (i.e. "the leak") will vary, since when gas is withdrawn slowly under isothermal conditions the subsequent pressure rise will be exponential with a decay constant $\lambda$, but under adiabatic conditions the pressure rise will be faster due to the additional effects of the gas reheating, giving an apparent rate constant $(\lambda+\lambda$ thermal) which changes with time.

The results obtained when " $\lambda$ " was measured at various time intervals after withdrawal of gas from the box showed that the actual physical leak of the box was only approximately $0.004 \mathrm{~s}^{-1}$ which would result in a time constant of $173 \mathrm{~s}$. However, under experimental conditions additional adiabatic-isothermal changes occur, so that the overall time constant of the box is $117 \mathrm{~s}\left(\lambda+\lambda\right.$ thermal $=0.006 \mathrm{~s}^{-1}$.

Since it is virtually impossible to derive a mathematical formula that could accurately correct for any adiabatic to isothermal changes during the course of the experiment and that would be valid under varying environmental conditions, differing size of the infants, and variable rates of $\mathrm{N}_{2} \mathrm{O}$ uptake, we have chosen to overcome this potential source of error by calculating both $\lambda$ and the calibration factor under conditions closely resembling those encountered experimentally.

Consequently, $\lambda$ is calculated from the pressure decay during a 20-s period after the slow withdrawal of air from the box $\left(1 \mathrm{ml} \mathrm{s}^{-1}\right)$ and thus represents decay due to both adiabaticisothermal changes and the physical leak of the box, 
while calibration is performed by the slow withdrawal of gas over a 20 -s period, the signal thus obtained being corrected for leak to obtain the true value.

It should be noted that, unlike Linderholm et al. (27), we have used only a single-rate constant in both adiabatic and isothermal conditions. This is because to a first approximation the rates of pressure change through heating and leakage into the box are both proportional to the pressure differences between atmosphere and the box.

\section{REFERENCES}

1. Astrom, H. R., K. H. Lin, and M. B. Mcllroy. 1973. Pulmonary capillary blood flow during normal spontaneous breathing in man. J. Appl. Physiol. 35: 823-829.

2. Ayotte, B., J. Seymour, and M. B. McIlroy. 1970. A new method for measurement of cardiac output with nitrous oxide. J. Appl. Physiol. 28: 863-866.

3. Bosman, A. R., A. J. Honour, G de J. Lee, R. Marshall, and F. D. Stott. 1964 Method for measuring instantaneous pulmonary capillary blood flow and right ventricular stroke volume in man. Clin. Sci (Oxf.) 26: 247-260.

4. Lee, G. de J., and A. B. DuBois. 1955. Pulmonary capillary bloodflow in man. J. Clin. Invest. 34: 13801390.

5. Brady, J. P., and H. Rigatto. 1971. Pulmonary capillary blood flow in newborn infant: a new method using the plethysmograph and nitrous oxide. Pediatrics. 48: 207215.

6. Cotton, E. K., J. J. Cogswell, and G. J. A. Cropp. 1971. Measurements of effective pulmonary blood flow in the normal newborn human infant. Pediatrics. 47: 520 528.

7. Dinwiddie, R., and G. Russell. 1972. The measurement of effective pulmonary capillary blood flow in the newborn, using low concentrations of nitrous oxide. Biol. Neonate. 21: $83-89$.

8. Eldridge, F. L., H. N. Hultgren, and M. E. Wigmore. 1954. The physiological closure of the ductus arteriosus in newborn infants: a preliminary report. Science (Wash. D. C.) 119: 731-732.

9. Kitterman, J. A., L. H. Edmunds, Jr., G. A. Gregory, M. A. Heymann, W. H. Tooley, and A. M. Rudolph. 1972. Patent ductus arteriosus in premature infants. Incidence, relation to pulmonary disease and management. N. Engl. J. Med. 287: 473-477.

10. Prec, K. J., and D. E. Cassels. 1955. Dye dilution curves and cardiac output in newborn infants. Circulation. 11: 789-798.

11. Siassi, B., C. Blanco, L. A. Cabal and A. G. Coran. 1976. Incidence and clinical features of patent ductus arteriosus in low-birthweight infants: A prospective analysis of 150 consecutively born infants. Pediatrics. 57: 347351.

12. Cross, K. W. 1949. The respiratory rate and ventilation in the newborn baby. J. Physiol. (Lond.) 109: 459-474.

13. Stocks, J., N. M. Levy, and S. Godfrey. 1977. A new apparatus for the accurate measurement of airway resistance in infancy.J. Appl. Physiol. Accepted for publication.

14. Mithoefer, J. C. 1959. Mechanism of pulmonary gas exchange and $\mathrm{CO}_{2}$ transport during breath holding. J. Appl. Physiol. 14: 706-710.

15. Dubowitz, L. M. S., V. Dubowitz, and C. Goldberg. 1970. Clinical assessment of gestational age in the newborn infant. J. Pediatr. 77: 1-10,

16. Hill, J. R., and K. A. Rahimtulla. 1965. Heat balance and the metabolic rate of new-born babies in relation to environmental temperature and the effect of age and weight on basal metabolic rate. J. Physiol. (Lond.) 180: 239265.

17. Scopes, J. W. 1966. Metabolic rate and temperature control in the human baby. Br. Med. Bull. 22: 88-91.

18. Dahlberg, G. 1940. Statistical methods for medical and biological students. Allen \& Unwin Ltd. London.

19. Bhakoo, O. N., and J. W. Scopes. 1974. Minimal rates of oxygen consumption in small-for-dates babies during the first week of life. Arch. Dis. Child. 49: 583-585.

20. Scopes, J. W., and I. Ahmed. 1966. Minimal rates of oxygen consumption in sick and premature newborn infants. Arch. Dis. Child. 41: 407-416.

21. Orme, R. L. E., E. A. Featherby, H. Rigatto, F. J. Cervantes, and J. P. Brady. 1973. Effective pulmonary blood flow in preterm infants with and without respiratory distress. A simple bedside method using nitrous oxide. Pediatrics. 52: 179-187.

22. Butler, J. 1965. Measurement of cardiac output using soluble gases. Handb. Physiol. Section 3. Respiration. 2: 1489-1503.

23. Chu, J., J. A. Clements, E. K. Cotton, M. H. Klaus, A. Y. Sweet, and W. H. Tooley. 1967. Neonatal pulmonary ischaemia. Part I: Clinical and physiological studies. Pediatrics. 40: 709-782.

24. Burnard, E. D., A. Grauaug, and R. E. Grey. 1966. Cardiac output in the newborn infant. Clin. Sci. (Oxf.) 31: $121-133$.

25. Heymann, M. A., and A. M. Rudolph. 1975. Control of the ductus arteriosus. Physiol. Rev. 55: 62-78.

26. Lister, G., J. I. E. Hoffman, and A. M. Rudolph. 1974. Oxygen uptake in infants and children: a simple method for measurement. Pediatrics. 53: 656-662.

27. Linderholm, H., P. Kimbel, D. H. Lewis, and A. B. DuBois. 1962. Pulmonary capillary blood flow during cardiac catheterisation. J. Appl. Physiol. 17: 135-141. 